\title{
Observations on the fermentation of carbohydrates along the gastro-intestinal tract of a fistulated cow
}

\author{
Blanche D. E. Gaillard and A. Th. van 't Klooster \\ Department of Animal Physiology, Agricultural University, Wageningen, the Netherlands
}

Received: 9 March 1973

\section{Summary}

1. A cow with cannulas in the proximal duodenum and terminal ileum was given three rations: a hay and concentrate ration (HC), a semi-synthetic ration (SS) and a grass ration $(\mathrm{G})$. Reference substances were used to calculate the quantities of digesta that passed the duodenal and ileal cannulas. Faeces were collected and measured quantitatively. To study the fermentation of carbohydrates in the different parts of the digestive tract the carbohydrates in food, digesta and faeces were divided in fractions: an ethanolsoluble fraction, $\alpha$-glucose polymers, fructosan, water-soluble polysaccharides other than $\alpha$-glucose polymers and fructosan, neutral-detergent-soluble polysaccharides and a neutral-detergent residue. The constituent sugars of these fractions were measured after hydrolysis.

2. On rations high in concentrates considerable amounts of $\alpha$-glucose polymers escaped rumen fermentation and were digested in the small intestine (SI) and caecum and colon (CC).

3. The amounts of other sugars digested in SI and CC were small compared to the fermentation in the stomachs (R).

4. Of the water-soluble fraction the major part was fermented in R. Apart from fermentation in CC digestion of this fraction also occurred in SI, indicating that besides the well known enzymatic hydrolysis of $\alpha$-glucose polymers also polysaccharides from mucus and bacteria are digested in SI.

5. The neutral-detergent-soluble polysaccharides were virtually absent in rations $\mathrm{HC}$ and $G$. There was an increase during passage through $R$ which was digested again in SI and CC.

6. With the exception of the water-soluble fraction on ration SS more sugars disappeared from the water-soluble and the detergent-soluble fractions in SI than in CC. It was reasoned that in $\mathrm{CC}$ the apparent digestibility was more influenced by addition of mucus and bacterial polysaccharides than in SI.

7. The neutral-detergent residue increased during passage through SI. On rations SS and $\mathrm{G}$ fermentation occurred in $\mathrm{CC}$ especially of glucose and xylose indicating that some cell-wall polysaccharides of the food were fermented here. It was suggested that a relatively large amount of readily available carbohydrates in $\mathbf{R}$ had lowered fermentation of these polysaccharides in $\mathrm{R}$. Of the contrasting results on ration $\mathrm{HC}$ no explanation could be given.

\section{Introduction}

In ruminants the fermentation of the carbohydrates mainly occurs in the rumen. A relatively small amount of digestible carbohydrate passes the pylorus and is digested 
in the lower gut. The level and site of this post-ruminal fermentation seems to be influenced by the composition of the ration. The carbohydrate fractions in the food are: mono- and disaccharides, fructosan, pectin, starch, hemicelluloses and cellulose. The first three are considered to be completely fermented in the rumen. On roughage diets very little starch as such or as storage polysaccharide in the micro-organisms escapes rumen fermentation and is digested in the small intestine. On high concentrate rations a substantial part of the digestible starch has been found to be digested posterior to the rumen, mainly in the small intestine but part of it even in caecum and colon. A review on the extent and sites of starch digestion has been given by Armstrong \& Beever (1969). Fermentation of digestible hemicelluloses and cellulose is mostly completed in the rumen (Porter \& Singleton, 1966; Watson et al., 1968; Topps et al., 1968; Gaillard \& van 't Klooster, 1969; Porter \& Singleton, 1971). On some occasions however, with rations high in concentrates (Little et al., 1967) or when the food is pelleted (Beever et al., 1972) hemicellulose and cellulose fermentation in the rumen is lowered and partly compensated by fermentation in caecum and colon.

The carbohydrates ingested with the food are not the only source of carbohydrates for post-ruminal fermentation. Also polysaccharides of bacterial and protozoal origin, synthesized in the rumen, pass with the digesta to the intestines. Mucopolysaccharides too are added to the digesta in stomachs and intestines. In most of the experiments mentioned above these polysaccharides from bacterial cell-walls and from glycoproteins will have been estimated as hemicelluloses or other fractions of the food carbohydrates thus influencing the results. So far it has not yet been possible to distinguish in the digesta and faeces between the carbohydrates from different origin, but by carrying out detailed analyses on food, duodenal and ileal contents and faeces we have tried to obtain some more information on the types of sugars that are fermented in the different parts of the gastro-intestinal tract of a cow receiving three different rations.

\section{Materials and methods}

\section{Experimental}

Samples of intestinal contents were obtained from a cow fitted with cannulas in the proximal duodenum and terminal ileum approximate to the caecum. Three different rations were offered to this cow in subsequent digestion experiments, i.e. a hay $(7 \mathrm{~kg} /$ day) and concentrate $(6 \mathrm{~kg} /$ day) ration $(\mathrm{HC})$ in Experiment 1, a semisynthetic ration (SS) composed of hay ( $3 \mathrm{~kg} / \mathrm{day}$ ), paper pulp ( $3 \mathrm{~kg} /$ day) and concentrates $(3.7 \mathrm{~kg} / \mathrm{day})$ in Experiment 2 , and a ration of freshly mown spring grass (11 kg dry matter/day) (G) in Experiment 3. In Experiments 1 and 2 the cow was fed twice daily. The grass in Experiment 3 was offered more spread over the day.

Preliminary feeding periods lasted for 10 days in Experiments 1 and 2 and for 5 days in Experiment 3. The experimental periods lasted for 5 days in Experiment 1 and for 7 days in Experiments 2 and 3. In these periods contents from the proximal duodenum and terminal ileum were sampled every 2 hours for 5 days (60 samples). These samples were bulked separately and stored at $4{ }^{\circ} \mathrm{C}$ until they were freeze-dried.

Faeces were collected in total during the experimental periods and representative samples dried at $60^{\circ} \mathrm{C}$.

Poly(ethylene glycol) (PEG) and chromium sesquioxide $\left(\mathrm{Cr}_{2} \mathrm{O}_{3}\right)$ were used to estimate the rate of flow of digesta past each of the intestinal cannulas. These indicators were 
delivered twice daily into the rumen via a rumen cannula. In the calculations the flow rate used was the mean of two values, one based on $\mathrm{Cr}_{2} \mathrm{O}_{3}$ and the other on PEG. In an earlier paper (van 't Klooster \& Rogers, 1969) the experimental techniques are described in detail. In the present paper stomachs refer to the whole ruminant stomach: rumen, reticulum, omasum and abomasum (R). Small intestine refers to the intestine between the proximal duodenal fistula and the terminal ileal fistula (SI) and caecum plus colon to the part of the gut distal to the ileal fistula (CC).

\section{Fractionation of carbohydrates}

The carbohydrates were separated in fractions depending on their solubility in different solvents (Fig. 1) and their monosaccharide composition determined. The fractions were:

- ethanol-soluble (mono- and disaccharides);

- $\alpha$-glucose polymer (starch and storage in micro-organisms);

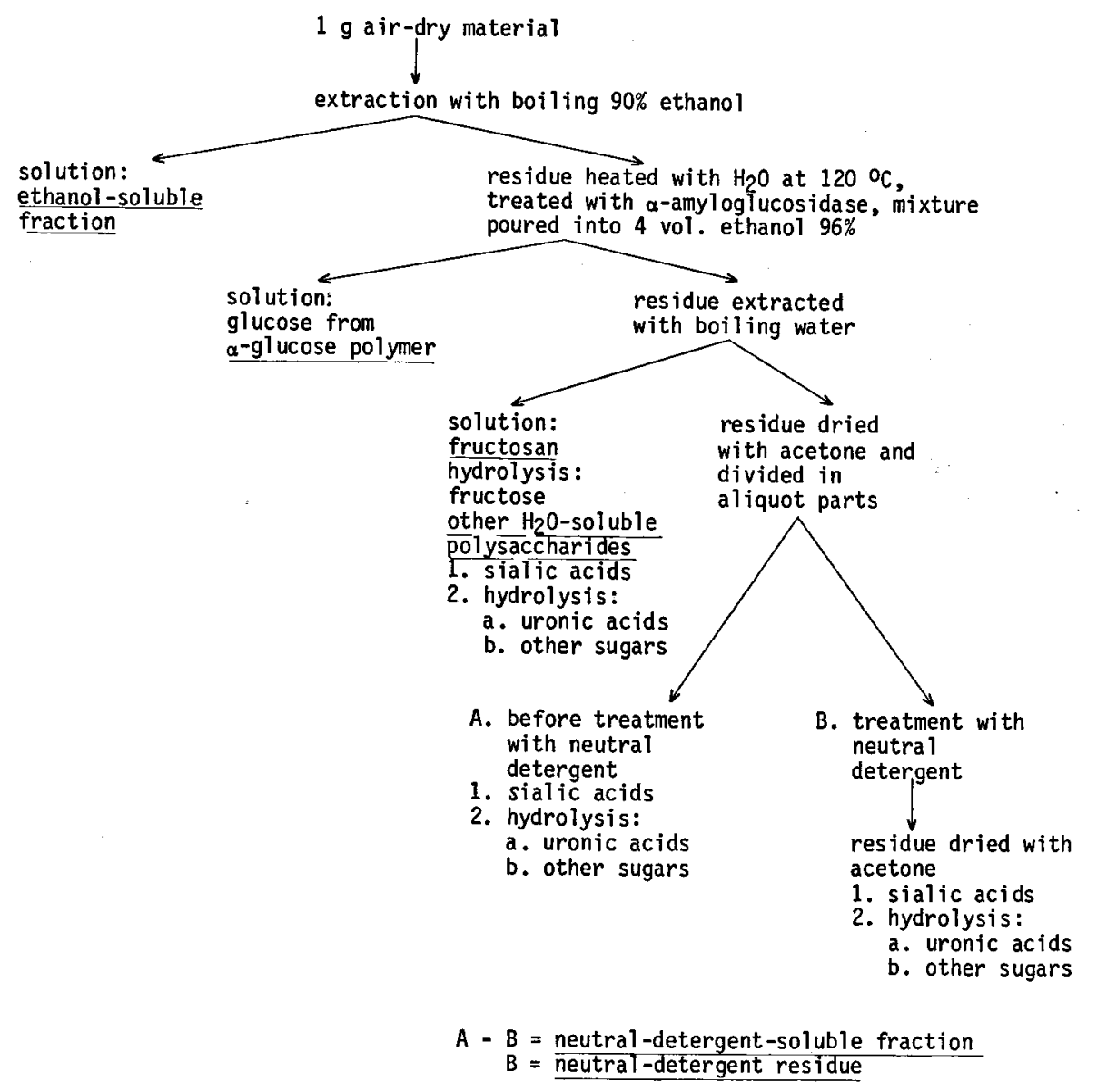

Fig. 1 Fractionation of the carbohydrates. 
- other water-soluble polysaccharides (fructosan, polysaccharides from glycoproteins, bacterial polysaccharides, etc.);

neutral-detergent-soluble polysaccharides (in this fraction we may find some degraded cell-wall polysaccharides from the food and polysaccharides from glycoproteins and micro-organisms);

- the neutral-detergent residue (in this fraction we will find the intact cell-wall polysaccharides from the food and probably in addition some from bacterial cell-walls).

Ethanol-soluble fraction. This fraction was obtained by twice extracting with boiling ethanol $90 \%$ for 1 hour. The ethanol was evaporated under reduced pressure, the remaining water solution was clarified with Carrez and the sugars estimated after hydrolysis in $0.02 \mathrm{~N} \mathrm{HCI}$ for 30 minutes in boiling water.

a-glucose polymers. The residue of the ethanol extraction was transferred to an Erlenmeyer flask with $30 \mathrm{ml}$ of water. The mixture was heated for 2 hours at $120^{\circ} \mathrm{C}$ in an autoclave. After cooling $10 \mathrm{mg} \alpha$-amyloglucosidase (E. Merck A.G.) was added in $2.5 \mathrm{ml} 2 \mathrm{M}$ acetate buffer $\mathrm{pH} 4.6$. Water was added to $50 \mathrm{ml}$ and the mixture kept at $60{ }^{\circ} \mathrm{C}$ in a thermostat bath with frequent shaking for 1 hour. An enzyme blanc was included. The mixture was then poured into $200 \mathrm{ml} 96 \%$ ethanol whilst stirring. All water-soluble polysaccharides were so precipitated and the supernatant ethanol solution contained only the glucose from the $\alpha$-glucose polymers. After evaporating the ethanol and clarifying the remaining water solution with Carrez the glucose was estimated.

Other water-soluble polysaccharides. The residue was extracted with boiling water. After filtration the solution was made up to $100 \mathrm{ml}$. Sialic acids were measured in $1-\mathrm{ml}$ quantities. Another part of the solution was hydrolysed in $2 \mathrm{~N}$ sulphuric acid. For this $75 \mathrm{ml}$ were added to $7.81 \mathrm{ml} 75 \%$ sulphuric acid in a $100-\mathrm{ml}$ measuring flask and the solution made up to volume. The flask was kept in boiling water for 6 hours. After cooling uronic acids, total sugar content adn the ratio of constituent sugars were determined. When fructosan was present, i.e. in hay and grass, $20 \mathrm{ml}$ of the water solution was acidified to $0.02 \mathrm{~N}$ with hydrochloric acid and hydrolysed for 30 minutes in boiling water after which sugar was measured.

Neutral-detergent-soluble polysaccharides. As it was difficult to estimate sugars in the neutral-detergent solution this fraction was determined indirectly. The residue after water extraction was dried with acetone, weighed after evaporation of the acetone and divided into three parts. In one part sialic acids were measured. Another part was hydirolysed with $3.75 \mathrm{ml} 72 \%$ sulphuric acid for 4 hours at $20 \pm 2{ }^{\circ} \mathrm{C}$. The mixture was transferred to an Erlenmeyer flask with $41.5 \mathrm{ml}$ of water, bringing the sulphuric acid concentration to $2 \mathrm{~N}$. Hydrolysis was continued in boiling water for 6 hours. After filtration the solution was made up to $200 \mathrm{ml}$ and uronic acids, total sugar content and the ratio of constituent sugars were determined in the solution.

The remaining part of the residue was boiled for 1 hour with neutral detergent (Van Soest, 1963). The residue was collected, washed with water and dried with acetone. On it the same determinations as described above were carried out. The neutral-detergentsoluble sugars were calculated by difference.

Neutral-detergent residue. The carbohydrate composition of this residue was determined in the previous section. 
Analyses

PEG was estimated according to Hydén (1955) and $\mathrm{Cr}_{2} \mathrm{O}_{3}$ as described by van 't Klooster et al. (1969).

For the sialic acid determinations to $1 \mathrm{ml}$ of the water extract was added $0.1 \mathrm{ml} \mathrm{N}$ sulphuric acid and to $30-40 \mathrm{mg}$ portions of the residues before and after the treatment with neutral detergent $2 \mathrm{ml} 0.1 \mathrm{~N}$ sulphuric acid. The tubes were flushed with nitrogen, closed and kept for 1 hour at $80^{\circ} \mathrm{C}$. On $0.2 \mathrm{ml}$ portions sialic acids were measured by the method of Warren (1959). In the hydrolysates uronic acids were measured by the carbazol method of Dische (1947) and total sugars after neutralization by the method of Hagedorn \& Jensen (1921). For the determination of the ratio of the constituent sugars parts of the hydrolysates were neutralized with barium carbonate. The solutions were concentrated under reduced pressure and the sugars separated by chromatography on SS paper No. 2040a with butanol-ethanol-water (7-2-2) as solvent and aniline phosphate as indicator. The individual sugars were measured after elution with water by the method of Hagedorn \& Jensen.

\section{Results and discussion}

The composition of the rations and their carbohydrate fractions is given in Table 1 . Table 2 shows the amount of each fraction (in g/day) that is fermented in the stomachs (R), small intestine (SI) and colon and caecum (CC). The digestion of the constituent sugars (in g/day) of the water-soluble fraction, the neutral-detergent-soluble fraction and the neutral-detergent residue is shown in Tables 3,4 and 5, respectively.

Apart from the ration $\mathrm{HC}$ where considerable amounts of $\alpha$-glucose polymer are digested in SI the total amounts of carbohydrates that are fermented in SI and CC are small compared to the amounts that are fermented in $\mathbf{R}(5-10 \%)$.

From the composition of the constituent sugars of the different carbohydrate fractions some information could be obtained about the origin of the fermented polysaccharides. Thus starch and storage glycogen are recognized as $\alpha$-glucose polymers. Glycoproteins of mucus are mainly composed of sialic acids, amino sugars, galactose, mannose and fucose (Gottschalk, 1966). Bacterial polysaccharides contain xylose, arabinose, rhamnose, mannose, galactose, glucose and amino sugars (Hoogenraad \& Hird, 1969; Smith \& McAllen, 1971). Unfortunately many sugars are found in plant cell-walls as well as in mucus glycoproteins and in bacterial polysaccharides with the exception of rhamnose which occurs only in bacterial polysaccharides and sialic acid which is a typical constituent of glycoproteins. Glycoproteins most probably do not contain glucose.

\section{$\alpha$-glucose polymer}

Fermentation of $\alpha$-glucose polymers mainly occurred in R, although on SS and G rations some digestion of $\alpha$-glucose polymer, probably mainly as storage polysaccharide, took place in SI and CC. O nration $\mathrm{HC}$ with a large amount of starch considerable quantities of $\alpha$-glucose polymer disappeared from SI and CC $(20.3 \%$ and $6.8 \%$ of total digestible starch, respectively). These results agree with the general findings reviewed by Armstrong \& Beever (1969). 
Table 1. Composition of the rations in $\mathrm{g} /$ day. All constituent sugars are expressed as anhydrosugars.

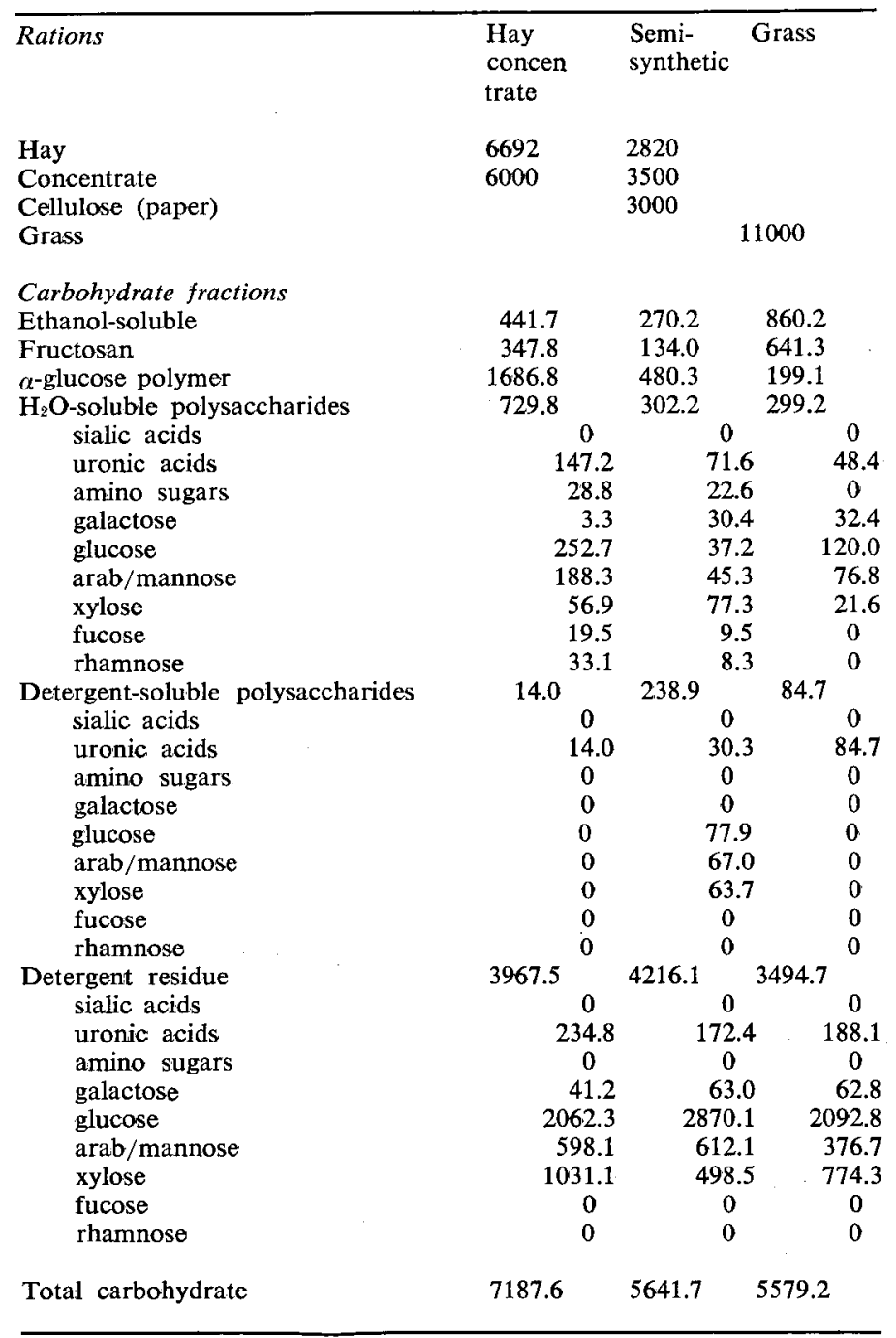

\section{Water-soluble fraction (Table 3)}

In ration $\mathrm{HC}$ this fraction was twice as large as in rations SS and G (Table 1). Its composition indicates the presence of pectic substances (polygalacturonic acid and araban) and some water-soluble hemicelluloses. The major part of it was fermented in $\mathbf{R}$. Increases in the amount of sialic acids, galactose, fucose and rhamnose together with the relatively low decrease of glucose and/or xylose indicated addition in $\mathbf{R}$ of polysaccharides from mucus and bacteria on all three rations. It is remarkable that on ration HC 
FERMENTATION OF CARBOHYDRATES ALONG THE COW'S GASTRO-INTESTINAL TRACT

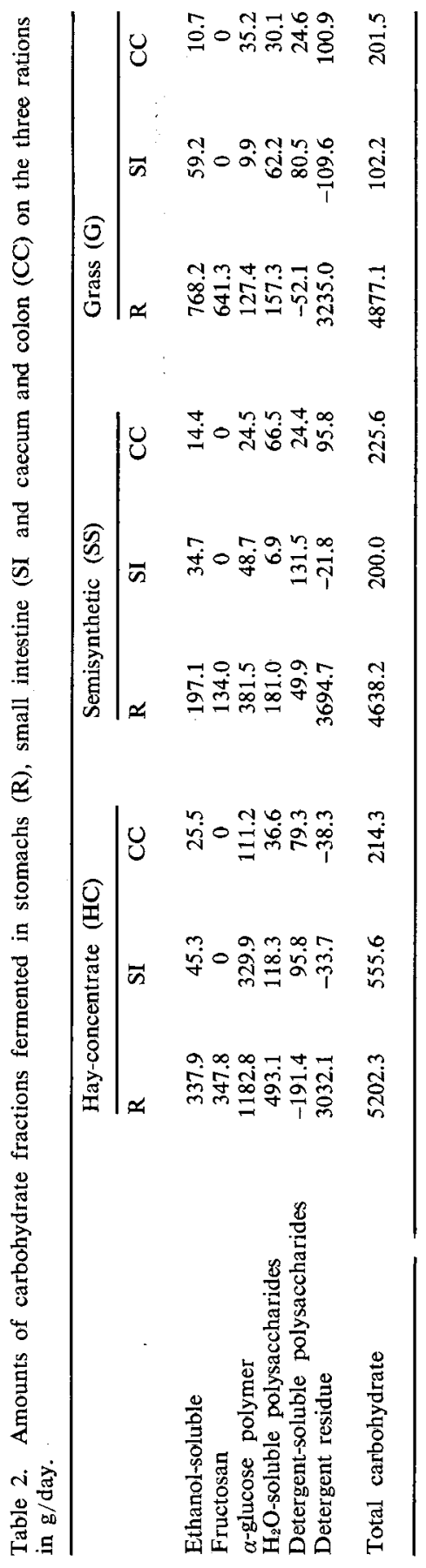

Neth. J. agric, Sci, 21 (1973) 
Table 3. Water-soluble fraction. Amounts of constituent sugars fermented in stomachs (R), smal] intestine (SI) and caecum and colon (CC) on the three rations in $\mathrm{g}$ anhydrosugar/day.

\begin{tabular}{|c|c|c|c|c|c|c|c|c|c|}
\hline & \multicolumn{3}{|c|}{ Hay-concentrate (HC) } & \multicolumn{3}{|c|}{ Semisynthetic (SS) } & \multicolumn{3}{|c|}{ Grass $(\mathrm{G})$} \\
\hline & $\mathbf{R}$ & SI & $\mathrm{CC}$ & $\mathbf{R}$ & SI & $\mathrm{CC}$ & $\mathbf{R}$ & SI & $\mathrm{CC}$ \\
\hline Sialic acids & -4.6 & 1.8 & 0.1 & -0.2 & 0.9 & 0.6 & 0 & -4.1 & 1.9 \\
\hline Uronic acids & 120.5 & 12.9 & 4.7 & 60.7 & 0 & 3.2 & 35.3 & 1.8 & 5.9 \\
\hline Amino sugars & 16.3 & 0.2 & 8.0 & 13.0 & 2.8 & 2.7 & -25.3 & 15.6 & 6.7 \\
\hline Galactose & -28.3 & 2.0 & 20.4 & 18.1 & -7.0 & 10.4 & 5.1 & 14.9 & 6.2 \\
\hline Glucose & 163.6 & 63.0 & 10.1 & 20.9 & -13.8 & 22.2 & 99.3 & 11.0 & 3.2 \\
\hline Arab/mannose & 176.3 & -1.3 & 2.8 & 27.7 & 3.8 & 10.7 & 64.0 & 3.9 & 2.3 \\
\hline Xylose & 33.7 & 15.2 & -10.2 & 57.9 & 11.3 & 1.3 & 7.1 & 5.9 & -0.3 \\
\hline Fucose & 3.9 & 9.3 & 0.3 & -3.9 & 1.8 & 4.1 & -8.3 & -2.0 & 4.0 \\
\hline Rhamnose & 11.7 & 15.2 & 0.4 & -13.2 & 7.1 & 11.3 & -19.9 & 15.2 & 0.2 \\
\hline
\end{tabular}

as well as on ration $\mathrm{G}$ more carbohydrates of this fraction disappeared in SI than in CC. Apart from the well known enzymatic hydrolysis of $\alpha$-glucose polymers other hydrolyses occurred in SI. Thus the disappearance of rhamnose, fucose and xylose together with relatively much glucose on rations $\mathrm{HC}$ and $\mathrm{G}$ could be explained by digestion of bacterial polysaccharides. On ration SS the addition of glucose and galactose could even indicate bacterial growth in SI. This may be caused by the large amount of easily accessible cellulose which promoted growth of Gram-negative bacteria. On ration $G$ the negative figures for sialic acids and fucose suggest a slight addition of mucus polysaccharides.

In $\mathrm{CC}$ bacterial growth and fermentation occurred, and also secretion of mucus and fermentation of its glycoproteins. The final results noted under $\mathrm{CC}$ in Table 3 only give the differences between the various activities. The composition of the sugars that disappeared from the water-soluble fraction in CC do not suggest fermentation of degraded hemicelluloses or cellulose.

\section{Neutral-detergent-soluble fraction (Table 4)}

in rations $\mathrm{HC}$ and $\mathrm{G}$ the neutral-detergent-soluble fraction only consisted of some pectin, in SS considerable amounts of glucose, arabinose and xylose were found, probably

Table 4. Neutral-detergent-soluble fraction. Amounts of constituent sugars fermented in stomachs (R), small intestine (SI) and caecum and colon (CC) on the three rations in $\mathrm{g}$ anhydrosugar/day.

\begin{tabular}{|c|c|c|c|c|c|c|c|c|c|}
\hline & \multicolumn{3}{|c|}{ Hay-concentrate (HC) } & \multicolumn{3}{|c|}{ Semisynthetic (SS) } & \multicolumn{3}{|c|}{ Grass (G) } \\
\hline & $\mathbf{R}$ & SI & $\mathrm{CC}$ & $\mathbf{R}$ & SI & $\mathrm{CC}$ & $\mathbf{R}$ & SI & $\mathrm{CC}$ \\
\hline Sialic acids & 0 & -0.9 & 0.5 & -0.6 & 0 & 0.1 & 0 & -0.3 & 0.3 \\
\hline Uronic acids & -15.0 & 23.9 & -2.1 & 19.1 & 0.7 & 8.0 & 77.5 & 2.2 & 0.6 \\
\hline Amino sugars & 0 & 0 & 0 & 0 & 0 & 0 & 0 & 0 & 0 \\
\hline Galactose & 0 & 0 & -12.6 & -3.9 & -4.6 & -2.7 & -17.2 & 16.5 & 0.4 \\
\hline Glucose & -116.4 & 25.2 & 91.2 & -22.2 & 79.3 & 10.1 & -22.4 & -17.2 & 19.6 \\
\hline Arab/mannose & 0 & 0 & -2.3 & 42.7 & 22.8 & 1.5 & -40.1 & 36.4 & -0.4 \\
\hline Xylose & -60.0 & 49.3 & 10.6 & 14.8 & 37.4 & 9.4 & -49.9 & 49.9 & -2.9 \\
\hline Fucose & 0 & 0 & 0 & 0 & -0.7 & 0.4 & 0 & -3.6 & 3.6 \\
\hline Rhamnose & 0 & -1.7 & -6.0 & 0 & -3.4 & -2.4 & 0 & -3.4 & 3.4 \\
\hline
\end{tabular}


originating from degraded paper cellulose and hemicelluloses. Because of the presence of these polysaccharides there is still a positive fermentation of this fraction in $R$. On rations $\mathrm{HC}$ and $\mathrm{G}$ these figures are negative possibly due to addition of partly degraded hemicelluloses and cellulose. Increases in the quantities of glucose, galactose and sialic acids in this fraction on ration SS indicated addition of bacterial polysaccharides and mucoproteins. On all three rations digestion of this fraction was higher in SI than in CC especially on the SS and G rations. Multiplication of bacteria and secretion of mucus occur in SI and $\mathrm{CC}$ at the same time as fermentation of the polysaccharides. The present results give the net effects (disappearance minus addition). Probably this influenced the apparent digestibility in CC more than in SI.

\section{Neutral-detergent residue (Table 5)}

This residue, composed mainly of cell-wall polysaccharides (hemicelluloses and cellulose), as could be expected was mainly fermented in $\mathrm{R}$. On all three rations there was an increase of this residue during passage throug the small intestine. On ration $G$ this addition was fermented again in $\mathrm{CC}$ resulting in a zero apparent digestibility of the cell-wall polysaccharides after $\mathbf{R}$. The composition of the polysaccharides added in SI on this ration indicated bacterial growth and probably secretion of mucus. On $\mathrm{HC}$ and SS rations the increase in SI probably also originated partly from bacterial polysaccharides. On rations SS and G the fermentation of glucose and xylose in CC was relatively high. This suggests that here hemicelluloses and cellulose from food were fermented. It is possible that the relatively large amount of readily available sugars in these rations have lowered fermentation of the cell-wall polysaccharides in R. Bacterial growth was again indicated by increases in rhamnose and fucose. Of the negative figures for this residue in $\mathrm{CC}$ no clear explanation could be given.

Table 5. Neutral-detergent residue. Amounts of constituent sugars fermented in stomachs (R), small intestine (SI) and caecum en colon (CC) on the three rations in $\mathrm{g}$ anhydrosugar/day.

\begin{tabular}{|c|c|c|c|c|c|c|c|c|c|}
\hline & \multicolumn{3}{|c|}{ Hay-concentrate (HC) } & \multicolumn{3}{|c|}{ Semisynthetic (SS) } & \multicolumn{3}{|c|}{ Grass $(G)$} \\
\hline & $\mathbf{R}$ & SI & $\mathrm{CC}$ & $\mathbf{R}$ & SI & $\mathrm{CC}$ & $\mathbf{R}$ & SI & $\mathrm{CC}$ \\
\hline Sialic acids & 0 & -1.4 & 0.6 & -0.6 & 0 & 0.1 & 0 & 0 & 0 \\
\hline Uronic acids & 195.9 & -13.1 & 5.4 & 139.4 & 5.1 & 7.4 & 171.0 & 0.1 & 6.2 \\
\hline Amino sugars & 0 & 0 & 0 & 0 & 0 & 0 & 0 & 0 & 0 \\
\hline Galactose & -14.2 & 15.3 & 19.8 & 47.6 & 5.9 & 0.2 & 62.8 & -22.4 & 10.0 \\
\hline Glucose & 1558.4 & 52.8 & -57.0 & 2584.2 & -29.8 & 69.9 & 1924.3 & -3.6 & 48.3 \\
\hline Arab/manose & 529.9 & -16.9 & 24.1 & 555.3 & 6.3 & 12.0 & 376.7 & -27.8 & 6.7 \\
\hline Xylose & 762.1 & -52.8 & -36.2 & 368.8 & -6.1 & 20.3 & 700.2 & -39.8 & 34.6 \\
\hline Fucose & 0 & 0 & 0 & 0 & 0 & -10.3 & 0 & -3.4 & -4.0 \\
\hline Rhamnose & 0 & -17.6 & 5.0 & 0 & -3.2 & -3.8 & 0 & -12.7 & -0.9 \\
\hline
\end{tabular}

\section{Acknowledgment}

The authors wish to thank Mrs R. Klunder-Vleer for assistance with the analyses. 


\section{References}

Armstrong, D. G. \& D. E. Beever, 1969. Post abomasal digestion of carbohydrate in the adult ruminant. Proc. Nutr. Soc. 28: 121-131.

Beever, D. E., J. F. Coelho da Silva, J. H. D. Prescott \& D. G. Armstrong, 1972. The effect in sheep of physical form and stage of growth on the sites of digestion of a dried grass. Br. J. Nutr. 28: 347-356.

Dische, Z., 1947. A new specific color reaction of hexuronic acids. J. biol. Chem. 167: 189-198.

Gaillard, B. D. E. \& A. Th. van 't Klooster, 1969. The digestion of the cell-wall constituents of roughages. Meded. Landb. Hogesch. 69: 20-25.

Gottschalk, A., 1966. Glycoproteins. Elsevier, Amsterdam.

Hagedorn, H. C. \& B. N. Jensen, 1921. Zur Mikrobestimmung des Blutzuckers mittels Ferricyanid Biochem. Z. 135: $46-58$.

Hoogenraad, N. J. \& F. J. R. Hird, 1969. The chemical composition of rumen bacteria and cellwalls from rumen bacteria. Br. J. Nutr. 24: 119-127.

Hydén, S., 1955. A turbidimetric method for the determination of higher polyethylene glycols in biological materials. K. Lantbr. Högsk. Annlr 22: 139-145.

Klooster, A. Th. van 't \& P. A. M. Rogers, 1969. The rate of flow of digesta and the net absorption of dry matter, organic matter, ash, nitrogen and water. Meded. Landb. Hogesch. 69: 3-19.

Klooster, A. Th. van 't, P. A. M. Rogers \& H. R. Sharma, 1969. Observations on the rate of flow of digesta through the duodenum of sheep and the recovery of polyethylene glycol and chromium sesquioxide from duodenal contents. Neth. J. agric. Sci. 17: 60-70.

Little, C. O., M. R. Karr \& B. W. Hayes, 1967. Ruminal and postruminal digestion of cellulose in steers. J. Anim. Sci. 26: 224.

Porter, P. \& A. G. Singleton, 1966. The digestion of pentosan in ruminants feeding on hay. J. Physiol. 183: $73 \mathrm{P}$.

Porter, P. \& A. G. Singleton, 1971. Digestion of carbohydrates of hay in small ruminants. Br. J. Nutr. 26: $75-88$.

Smith, R. H. \& A. B. McAllan, 1971. Bacterial carbohydirates formed in the rumen and their contribution to digesta entering the duodenum. Proc. Nutr. Soc. 31: 28A.

Topps, J. H., R. N. B. Kay \& E. D. Goodall, 1968. Digestion of concentrate and of hay diets in the stomach and intestines of ruminants. Br. J. Nutr. 22: 261-280.

Van Soest, P. J., 1963. Use of detergents in the analysis of fibrous feeds. J. Ass. Off. Agric. Chem. 46: 825-829.

Warren, L., 1959. The thiobarbituric acid assay of sialic acids. J. biol. Chem. 234: 1971-1975.

Watson, M. J., G. P. Savage, I. Brown \& D. G. Armstrong, 1968. Sites of disappearance of apparently digestible cellulose and apparently digestible $\alpha$-linked glucose polymers in the digestive tract of a cow receiving dried grass-concentrate diets. Proc. Nutr. Soc. 31: 99A-100A. 